\title{
Update on insulin treatment for dogs and cats: insulin dosing pens and more
}

This article was published in the following Dove Press journal:

Veterinary Medicine: Research and Reports

15 April 2015

Number of times this article has been viewed

\section{Ann Thompson' \\ Patty Lathan ${ }^{2}$ \\ Linda Fleeman ${ }^{3}$}

'School of Veterinary Science, The University of Queensland, Gatton, QLD, Australia; ${ }^{2}$ College of Veterinary Medicine Mississippi State University, Starkville, MS, USA; ${ }^{3}$ Animal Diabetes Australia, Melbourne, VIC, Australia
Correspondence: Linda Fleeman Animal Diabetes Australia, Rowville Veterinary Clinic, 919 Stud Road, Rowville, VIC 3I78, Australia

Tel +61397631799

Fax +6I3 97637111

Email I.fleeman@animaidiabetesaustralia. com.au
Abstract: Insulin therapy is still the primary therapy for all diabetic dogs and cats. Several insulin options are available for each species, including veterinary registered products and human insulin preparations. The insulin chosen depends on the individual patient's requirements. Intermediate-acting insulin is usually the first choice for dogs, and longer-acting insulin is the first choice for cats. Once the insulin type is chosen, the best method of insulin administration should be considered. Traditionally, insulin vials and syringes have been used, but insulin pen devices have recently entered the veterinary market. Pens have different handling requirements when compared with standard insulin vials including: storage out of the refrigerator for some insulin preparations once pen cartridges are in use; priming of the pen to ensure a full dose of insulin is administered; and holding the pen device in place for several seconds during the injection. Many different types of pen devices are available, with features such as half-unit dosing, large dials for visually impaired people, and memory that can display the last time and dose of insulin administered. Insulin pens come in both reusable and disposable options. Pens have several benefits over syringes, including improved dose accuracy, especially for low insulin doses.

Keywords: diabetes, mellitus, canine, feline, NPH, glargine, porcine lente

\section{Introduction}

Insulin therapy is the cornerstone of management for diabetic dogs and cats, and many insulin types have been shown to be effective. Traditionally, insulin has been administered using an insulin syringe, but insulin pens have become readily available over the past few years. Insulin dosing pens are designed to be used by people with no formal medical training with the goal of making the task of measuring and administering insulin doses easier, less painful, and more accurate and precise. They can provide the same benefit for diabetic animals and their owners. An important advantage of insulin dosing pens is that much of the confusion and difficulty of measuring insulin using syringes is eliminated.

The wide range and variety of insulin products that are currently available might seem overwhelming to clinicians preparing to treat a diabetic dog or cat. They could therefore be tempted to use a traditional familiar product rather than consider a new option which might provide clinical benefit for their patient or practical benefit for the owner. This paper aims to provide a comprehensive overview of currently available insulin products that can be used to treat canine and feline diabetes. This will allow veterinarians to make informed choices about the most appropriate and practical treatment option for individual cases. 


\section{Available insulin products}

A large number of insulin preparations are available for human use, but still only two are registered for veterinary use (Table 1). Many human diabetics now receive long-acting basal (peakless) insulin that is topped up at meal times with short-acting, rapid-onset insulin bolus injections to control postprandial hyperglycemia in an attempt to mimic normal pancreatic insulin secretion. This shift in management of human diabetes resulted in many intermediate-acting insulin products being removed from the market several years ago. Some of the discontinued insulin preparations were used off-label in veterinary practice, and their withdrawal required many diabetic dog and cat patients to change insulin types.

The insulin products currently registered for veterinary use are Caninsulin ${ }^{\circledR} /$ Vetsulin $^{\circledR}$, and ProZinc ${ }^{\circledR}$. Caninsulin/ Vetsulin is porcine lente insulin registered for use in both dogs and cats, and has been available worldwide for many years. Supply was disrupted in the USA in 2009 due to manufacturing issues; it was reintroduced to the USA market in April 2013, with a different label recommendation for the insulin to now be shaken prior to administration. Caninsulin/ Vetsulin has an intermediate duration of action. ProZinc (Boehringer Ingelheim) is a protamine zinc insulin (PZI) product that is registered for use in cats but can also be used to manage diabetes in dogs. ${ }^{1}$ This insulin preparation is not available worldwide. Both veterinary insulin types are less concentrated than human insulin at $40 \mathrm{U} / \mathrm{mL}$. To avoid dosing errors, it is recommended to always administer $40 \mathrm{U} / \mathrm{mL}$ insulin with either U40 syringes or the manufacturer's insulin dosing pen.

All other insulin products used in veterinary practice are prescribed off-label. Almost all of these insulin preparations have a concentration of $100 \mathrm{U} / \mathrm{mL}$ (the exceptions are Humulin $\mathrm{R}^{\circledR} 500 \mathrm{U} / \mathrm{mL}$ and Degludec $200 \mathrm{U} / \mathrm{mL}$ ). Several human insulin types have been used extensively in veterinary medicine, including the traditionally available insulin preparations, such as regular (crystalline), neutral protamine Hagedorn (NPH or isophane), and NPH insulin mixes. More recently, some of the newer human preparations, including glargine and detemir, have gained favor in managing pets with diabetes.

There is limited published information on the use of some newer insulin preparations in veterinary patients. Lispro, aspart, and glulisine are all rapid-onset, short-acting human recombinant insulin. These insulin products are used in human diabetics instead of crystalline insulin because they have a more rapid onset of action, which is ideal as they can be administered at meal times rather than 30 minutes prior.
Lispro insulin has been shown to be as safe and effective as crystalline insulin when given as a constant infusion rate to dogs with diabetic ketoacidosis. ${ }^{2}$ If crystalline insulin is removed from the market in the future, then lispro can be used as an alternative in veterinary patients.

NPH is the only intermediate human insulin still available, and has been used to treat canine diabetes mellitus. ${ }^{3}$ The NPH mixes of insulin such as Mixtard 30/70 ${ }^{\circledR}$ or Humulin $30 / 70^{\circledR}$ are available in some countries, and have a similar action to lente insulin. These insulin products contain 30\% rapid-acting regular insulin and 70\% intermediate-acting NPH and are administered twice daily. They can be administered at the time of feeding because the regular insulin acts promptly to control the postprandial hyperglycemia.

The available long-acting (basal) insulin preparations are glargine and detemir. Recently, Eli Lilly has been granted authorization to market glargine as Abasria ${ }^{\circledR}$ in Europe. Both glargine and detemir have been shown to give good glycemic control in diabetic cats. ${ }^{4-6}$ Since it has the same pharmacokinetic profile as regular insulin when injected intravenously or intramuscularly, glargine has also been used to treat ketoacidosis in feline patients. ${ }^{7}$ Glargine or detemir may be used to treat canine diabetes, although these longeracting insulin products are considered less predictable than intermediate-acting insulin in dogs.

Other insulin preparations worth mentioning are Degludec (Tresiba ${ }^{\circledR}$, Novo Nordisk) and Afrezza ${ }^{\circledR}$ (Sanofi and MannKind). Degludec insulin is an ultra-long-acting insulin approved for launch in the European Union and Japan. It is a human recombinant insulin that may last up to 42 hours, and is available in both $100 \mathrm{U} / \mathrm{mL}$ and $200 \mathrm{U} / \mathrm{mL}$ preparations. Degludec has been shown to decrease nocturnal hypoglycemia in people compared with glargine. ${ }^{8}$ Afrezza is a dry-powder formulation of recombinant human regular insulin recently approved by the US Food and Drug Administration (FDA). This is a rapid-acting insulin that is used in combination with basal insulin. The insulin is freeze-dried and administered by an inhaler. The insulin dissolves once in contact with the lungs and is rapidly adsorbed. The product is inhaled after meals to control postprandial hyperglycemia. Its use is not recommended in patients with underlying respiratory disease, and the long-term effects on the respiratory system are still unknown. One study has shown efficacy of inhaled insulin in healthy cats; however, due to the short duration of activity, the authors noted that inhaled insulin is unlikely to be an effective sole treatment in cats. ${ }^{9}$ To the authors' knowledge, no studies on diabetic veterinary patients have been performed with 


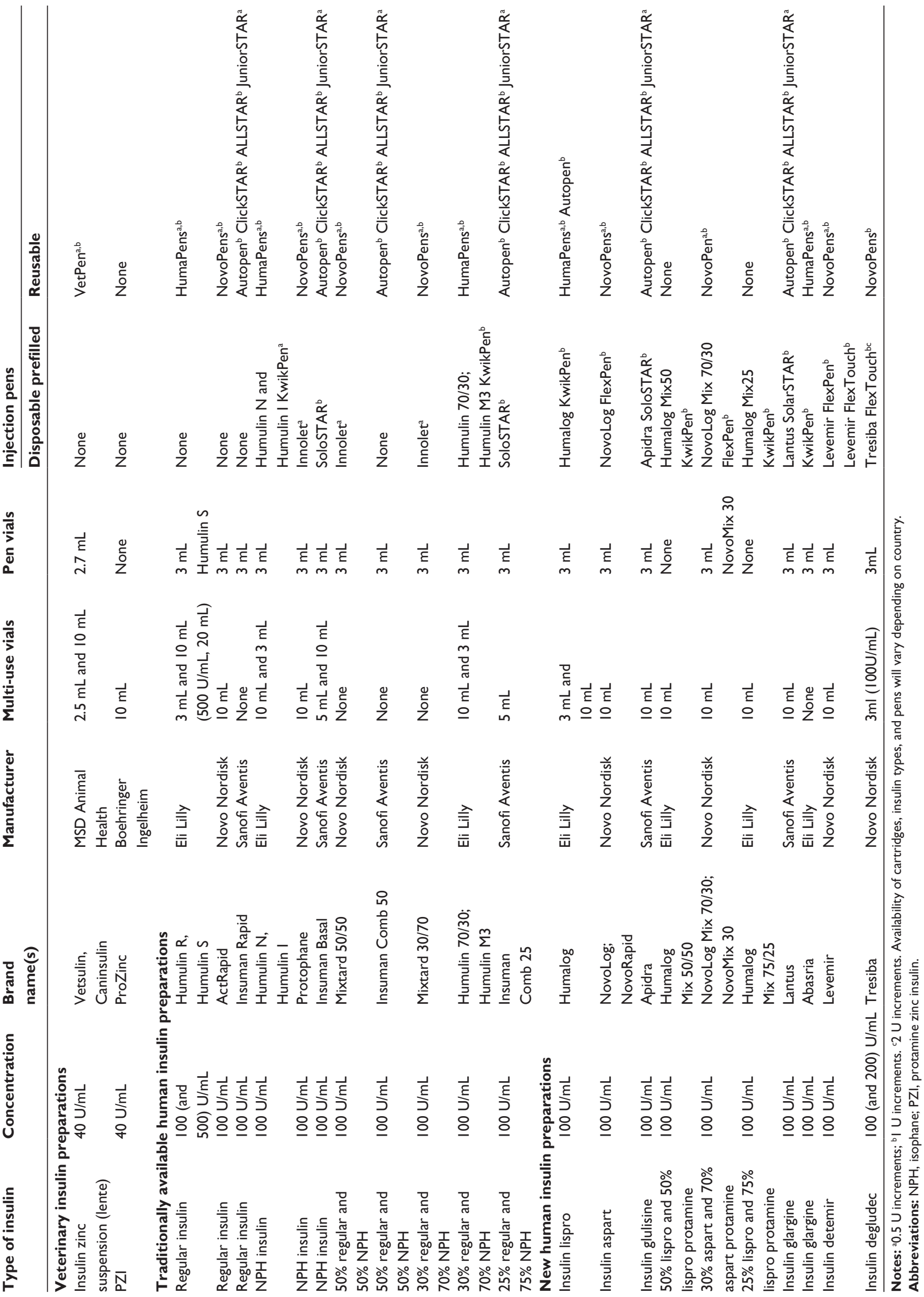


these insulin products, and their use in veterinary patients at this time seems limited.

\section{Insulin treatment for diabetic dogs}

Historically, the most universally used types of maintenance insulin in dogs have been NPH and lente insulin. Over the past few years, however, additional insulin options have been explored, partly due to the availability of newer insulin analogs for human use (such as detemir and glargine), and partly due to intermittent availability of lente insulin. The most recent canine studies have evaluated the use of NPH, porcine lente, glargine, detemir, and recombinant human PZI insulin preparations. Unfortunately, for logistical reasons, large controlled studies comparing the efficacies of different types of insulin in diabetic dogs have not been published.

NPH insulin was named after Hans Christian Hagedorn, who discovered that the addition of protamine to insulin prolongs its activity. The duration of action of NPH is between 4 and 10 hours in dogs. ${ }^{3}$ Although NPH insulin is the insulin of choice for some clinicians, the duration of activity is too short for twice-daily dosing in some dogs. The recommended starting dose is $0.25-0.50 \mathrm{U} / \mathrm{kg}$ every 12 hours. In one study that included well controlled diabetic dogs, the mean dose of NPH insulin was 0.63 (range 0.40-0.97) $\mathrm{U} / \mathrm{kg}$ every 12 hours. $^{3}$

NPH is a recombinant human insulin made by nonpathogenic bacteria; the strain used depends upon the name brand. Novolin $\mathrm{N}^{\circledR}$ and Humulin $\mathrm{N}^{\circledR}$ are biosynthesized by modified Saccharomyces cerevisiae and Escherichia coli bacteria, respectively, and are "biosimilar". ${ }^{10,11}$ The structure of the insulin products is identical. However, veterinarians on Veterinary Information Network have reported apparent alterations in glycemic control following unrequested substitution of Novolin $\mathrm{N}$ for Humulin $\mathrm{N}$ by human pharmacists due to the decreased cost of Novolin $\mathrm{N}$ in some stores. ${ }^{12}$ Although there are several other possible reasons for changes in diabetic regulation in dogs, and there have been no published studies evaluating changes in regulation following switches between biosimilar insulin preparations, it seems prudent to continue patients on the same brand of insulin when possible.

Since porcine insulin has the same amino acid sequence as canine insulin, porcine lente insulin zinc suspension (Vetsulin in the USA; Caninsulin everywhere else) is a rational choice for use in dogs. It contains $65 \%$ crystalline zinc insulin and 35\% amorphous zinc insulin (although the proportions of the two components are still described in some countries by the conventional product label of $70 \%$ and $30 \%$, respectively), resulting in two peaks in insulin concentra- tion at 4 and 11 hours, and lasts approximately 16 hours in dogs. ${ }^{13,14}$ Thus, twice-daily dosing is necessary in most dogs, with a recommended starting dose of $0.25-0.50 \mathrm{U} / \mathrm{kg}$ every 12 hours. Due to the suspension of two types of insulin, the manufacturer recommends that porcine lente insulin zinc suspension be shaken vigorously prior to administration.

Detemir $\left(\right.$ Levemir $\left.^{\circledR}\right)$ is a long-acting, recombinant insulin analog. Its prolonged duration of action is due to its binding to and slow release from albumin. Little data are available on the use of detemir in diabetic dogs, but two small studies reported effective control of hyperglycemia, but hypoglycemia (or clinical signs that may be associated with hypoglycemia) occurred in 4/10 dogs in one of the studies. ${ }^{15,16}$ Detemir appears to be a promising option for use in dogs in which the duration of action of NPH or porcine lente insulin is too short, but close monitoring of blood glucose concentration by owners at home is necessary to avoid hypoglycemia. Detemir insulin has a much more potent action in dogs than it does in humans. The modifications made to the insulin molecule in the production of detemir (to allow it to bind to albumin) cause detemir to bind to the human insulin receptor only $25 \%$ as avidly as human insulin. Thus, the marketed formulation was produced to have four times as much insulin per unit as other insulin preparations ( $24 \mathrm{nmol}$, as opposed to $6 \mathrm{nmol}$ ). However, detemir appears to bind to canine insulin receptors with more affinity than it does to human receptors. ${ }^{17}$ Thus, the recommended starting dose for diabetic dogs is $0.1 \mathrm{U} / \mathrm{kg}$ every 12 hours. For this reason, the use of detemir in smaller dogs $(<10 \mathrm{~kg})$ is problematic and often not practical.

Glargine (Lantus ${ }^{\circledR}$ ) is a long-acting, recombinant insulin analog that forms subcutaneous microprecipitates, allowing for slow absorption and a prolonged duration of activity. In humans, glargine is said to be "peakless". Two published studies have evaluated its use in dogs with naturally occurring diabetes mellitus. One study identified an unpredictable nadir in almost all of the glucose curves, whereas the other study found no difference between the mean minimum and maximum blood glucose concentrations (peakless). ${ }^{15,18}$ Dogs in the study by Hess and Drobatz were also placed on a diet high in soluble fiber at the time of enrollment, which might have contributed to different findings. Both studies concluded that glargine can be used to obtain good diabetic control in dogs. The median dose at the end of the studies was $0.5-0.6 \mathrm{U} / \mathrm{kg}$ every 12 hours, and their recommended starting dose was $0.3 \mathrm{U} / \mathrm{kg}$ every 12 hours; however, these authors find that a range of $0.25-0.50 \mathrm{U} / \mathrm{kg}$ every 12 hours similar to other insulin types (except detemir) is clinically appropriate. 
Recombinant human protamine zinc insulin (rhPZI, ProZinc), is a long-acting insulin, which is approved by the FDA for the treatment of feline (but not canine) diabetes mellitus in the USA. Beef/pork source PZI is no longer commercially available. One small study found that rhPZI was effective in controlling glycemia in a majority of 17 diabetic dogs, although prolonged duration of effect (nadir 10-12 hours post-insulin in some dogs) could possibly lead to hypoglycemia in some dogs. ${ }^{19}$ The median rhPZI dose at the end of the study was $0.9 \mathrm{U} / \mathrm{kg}$, with a recommended starting dose of $0.5 \mathrm{U} / \mathrm{kg}$ in dogs. Although neither glargine nor rhPZI are generally recommended as first-line insulin treatment in dogs, they are options for when the duration of activity of NPH or porcine lente insulin is too short. Recommended starting doses for insulin treatment in dogs are listed in Table 2.

\section{Insulin treatment for diabetic cats}

Currently, the most frequently recommended insulin preparations for use in cats are glargine, rhPZI, and porcine lente zinc suspension, and detemir has also been evaluated. Although NPH has been used in the past, the duration of activity in cats (less than 8 hours) is too short for twice-daily dosing. ${ }^{20}$

Glargine, rhPZI, porcine lente, and detemir insulin have all been demonstrated to achieve glycemic control in cats with twice-daily dosing. ${ }^{5,21-23}$ The recommended starting dose is typically $0.25-0.50 \mathrm{U} / \mathrm{kg}$ every 12 hours (rounded down to the nearest unit, and generally $\leq 2 \mathrm{U} /$ cat every 12 hours). It is worth noting that due to species differences in metabolism, detemir is not as potent in cats as in dogs, so standard insu-

Table 2 Recommended starting doses of insulin for dogs and cats

\begin{tabular}{|c|c|}
\hline Insulin type & Dose \\
\hline \multicolumn{2}{|c|}{$\begin{array}{l}\text { Recommended starting doses of insulin for uncomplicated } \\
\text { diabetic dogs }\end{array}$} \\
\hline Lente & $0.25-0.50 \mathrm{U} / \mathrm{kg}$ every 12 hours \\
\hline $\mathrm{NPH}$ & $0.25-0.50 \mathrm{U} / \mathrm{kg}$ every 12 hours \\
\hline NPH mixes & $0.25-0.50 \mathrm{U} / \mathrm{kg}$ every 12 hours \\
\hline \multicolumn{2}{|c|}{$\begin{array}{l}\text { Recommended starting doses of insulin for dogs that do not } \\
\text { respond to lente or NPH }\end{array}$} \\
\hline Glargine & $0.50 \mathrm{U} / \mathrm{kg}$ every 12 hours \\
\hline rhPZI & $0.50 \mathrm{U} / \mathrm{kg}$ every 12 hours \\
\hline Detemir & $0.10 \mathrm{U} / \mathrm{kg}$ every 12 hours \\
\hline \multicolumn{2}{|c|}{ Recommended starting doses of insulin for diabetic cats } \\
\hline Glargine & $0.25-0.50 \mathrm{U} / \mathrm{kg}$ every 12 hours \\
\hline rhPZI & $0.25-0.50 \mathrm{U} / \mathrm{kg}$ every 12 hours \\
\hline Lente & $0.25-0.50 \mathrm{U} / \mathrm{kg}$ every 12 hours \\
\hline Detemir & $0.25-0.50 \mathrm{U} / \mathrm{kg}$ every 12 hours \\
\hline
\end{tabular}

Note: Estimated ideal body weight rather than actual body weight should be used for thin or overweight animals.

Abbreviations: $\mathrm{NPH}$, isophane; rhPZI, recombinant human protamine zinc insulin. lin doses are recommended in cats. Recommended starting insulin doses for cats are listed in Table 2.

In addition to availability, ease of use, and expense, a major factor influencing insulin choice for diabetic cats is remission rate. Remission has been documented using each of these insulin types. One small study showed that use of glargine insulin resulted in a higher remission rate than use of either PZI or porcine lente insulin. ${ }^{6}$ However, a larger study verifying these results has not been published, and the remaining studies evaluating remission rates in diabetic cats have been variably controlled for predisposing and concurrent conditions, duration of diabetes, diet, monitoring frequency, and other factors, making it extremely difficult to compare the effect of insulin type. For example, Roomp and Rand showed a $64 \%$ remission rate in cats fed a low-carbohydrate diet when owners checked blood glucose concentration at least three times daily and adjusted glargine dose according to an algorithm, and a $67 \%$ remission rate using a similar protocol with detemir. ${ }^{22}$ Bennett et al achieved a similar remission rate of $68 \%$ in cats fed a low-carbohydrate diet and monitored using clinical parameters and fructosamine concentrations, with most cats receiving PZI. ${ }^{24}$ In a retrospective study, Zini et al reported a $56 \%$ remission rate in cats using porcine lente insulin and a $72 \%$ remission rate in cats using glargine, but diet and monitoring procedure were not controlled due to the retrospective nature of the study. ${ }^{25}$ Despite the inconstancies in control of diet and monitoring, these studies suggest that glargine, and likely detemir, facilitate the highest remission rate in diabetic cats, particularly when a low-carbohydrate diet and intensive monitoring are employed. However, both PZI and porcine lente insulin can result in remission rates $>50 \%$ as well.

In many countries, rhPZI is now commercially available as ProZinc, but commercial production of PZI has been intermittent in the past. As a result, many compounding pharmacies offer their own formulations. Since they are compounded, these products are not approved by the FDA. However, the United States Pharmacopeia (USP), an independent organization that sets standards for the pharmaceutical industry, sets specifications for PZI. A recent study evaluated various USP specifications in vials of PZI from 12 different compounding pharmacies, using three bottles of each product at four different time points. Specifications evaluated included endotoxin content, $\mathrm{pH}$, zinc content, insulin content, and other factors that could influence insulin pharmacokinetics. The study found that only one of the products met all USP specifications in all vials tested, and that use of these compounded insulin products could result in 
inconsistent glycemic control. ${ }^{26}$ Thus, the use of compounded insulin is not recommended.

The use of insulin in smaller veterinary patients often leads veterinarians to consider dilution of insulin. However, the accuracy and ease of use of insulin pens in patients that require lower doses of insulin has decreased the need for dilution. For some of the human insulin preparations, such as regular and NPH (for example, Humulin R, Humulin N, and Novolin N), a diluent and sterile vials can be purchased from the manufacturer, and the resultant diluted suspension can be used for up to 30 days. Alternatively, regular and NPH insulin can be diluted with saline for immediate use, but should not be kept for longer because of stability concerns. A standard dilution of 1:10 (10 U/mL) is recommended. The formation of microprecipitates is $\mathrm{pH}$-dependent for glargine insulin, and dilution is not recommended since it will significantly change the pharmacokinetics and make it similar to using regular insulin. No information for dilution of detemir or porcine lente zinc suspension is available, so dilution is not recommended. ${ }^{27}$

\section{Insulin dosing pens: why use them?}

Insulin dosing pens have been shown in people to decrease the anxiety, discomfort, and social embarrassment associated with administration of insulin. In a study where over 1,300 diabetics compared using pens with using insulin syringes, $90 \%$ of people reported no or minimal pain with the pen injection compared with $50 \%$ using standard syringes. ${ }^{28}$ In the same study, $92 \%$ of pen users thought the pens were easy to use compared with $39 \%$ of syringe users, and $91 \%$ would recommend pens to others.

Pens have greater dose accuracy when compared with insulin syringes, especially with low doses of insulin. As with many of our veterinary patients, low doses of insulin, commonly less than $5 \mathrm{U}$, are used to treat diabetic infants and children. In these patients, dosing accuracy is essential because overdose may result in hypoglycemia. Similar to the situation with pets, infants cannot verbalize that they are experiencing hypoglycemia which may therefore go unnoticed until more serious symptoms arise. Several studies have shown that dosing accuracy is increased when using a pen compared with a syringe. In these studies, either pediatric nurses or people experienced in using syringes drew up the insulin doses. In one study, three different pens were compared with insulin syringes. ${ }^{29}$ The target dose was $1 \mathrm{U}$. The pen doses varied from $0.92 \mathrm{U}$ to $1.10 \mathrm{U}$, compared with the syringes that ranged from $1.23 \mathrm{U}$ to $1.34 \mathrm{U}$. In all accuracy studies, syringes tend to overdose low volumes of insulin. Casella et al demonstrated that pediatric nurses when attempting to deliver a $0.5 \mathrm{U}$ syringe dose on average drew up almost double the intended dose. ${ }^{30,31}$ Syringes can be difficult to use, especially for those with visual or dexterity problems. Some pens have features including audible clicks, so if the numbers cannot be well visualized the number of clicks can be counted to ensure the correct dose is dialed. The Innolet ${ }^{\circledR}$ device (Figure 1) is made specifically for people with vision or dexterity problems, and features a large dial so that the number of units can be easily seen. As pens become more advanced, features are added such as dial back and memory features that record the time and date of each dose. In certain pens, the dose dial cannot move backward; if too high a dose is dialed up, the dose needs to be dispelled and then the correct dose can be set. In newer pens, the dial can move up or down. Many pens also offer a feature that will not allow the dose of insulin to be set higher than the volume of insulin remaining in the cartridge. Pens with memory may also be of use in veterinary patients, especially in households where more than one person administers the pet's insulin. The pens can show the units and time of the last dose administered; this may decrease the risk of veterinary patients being double-dosed. Disposable pens that are prefilled with insulin (Figure 2) are sometimes the most practical option for veterinary patients, because they are simple to prescribe and require only a supply of pen needles to begin dosing. However, reusable pens that accept insulin cartridges may provide additional benefits, such as $0.5 \mathrm{U}$ dosing increments (Figure 3 ) or use of a veterinary registered insulin product (Figure 4).

There are six steps to proper storage and administration of insulin with a pen device: ${ }^{32}$

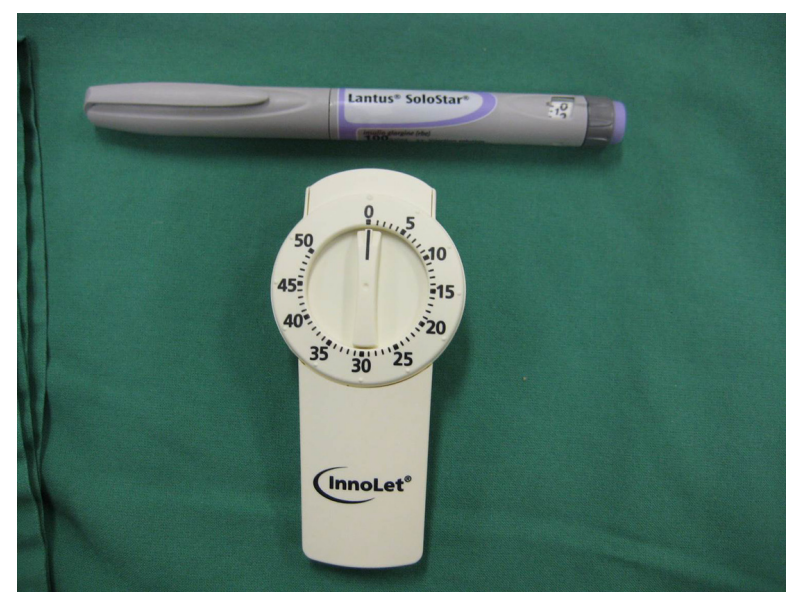

Figure I Innolet ${ }^{\circledR}$ pen device with a large dose selector dial for people with impaired vision or dexterity (bottom) compared with a more standard pen (Lantus ${ }^{\circledR}$ ) device (top). 

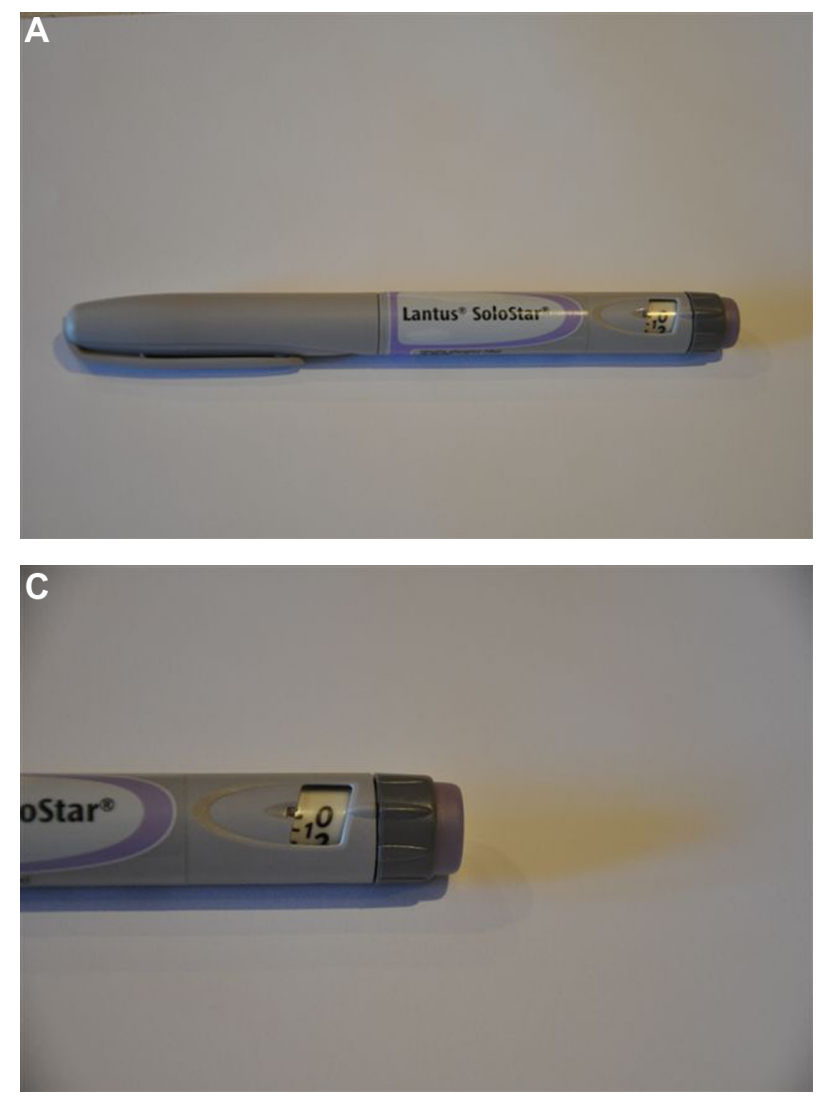
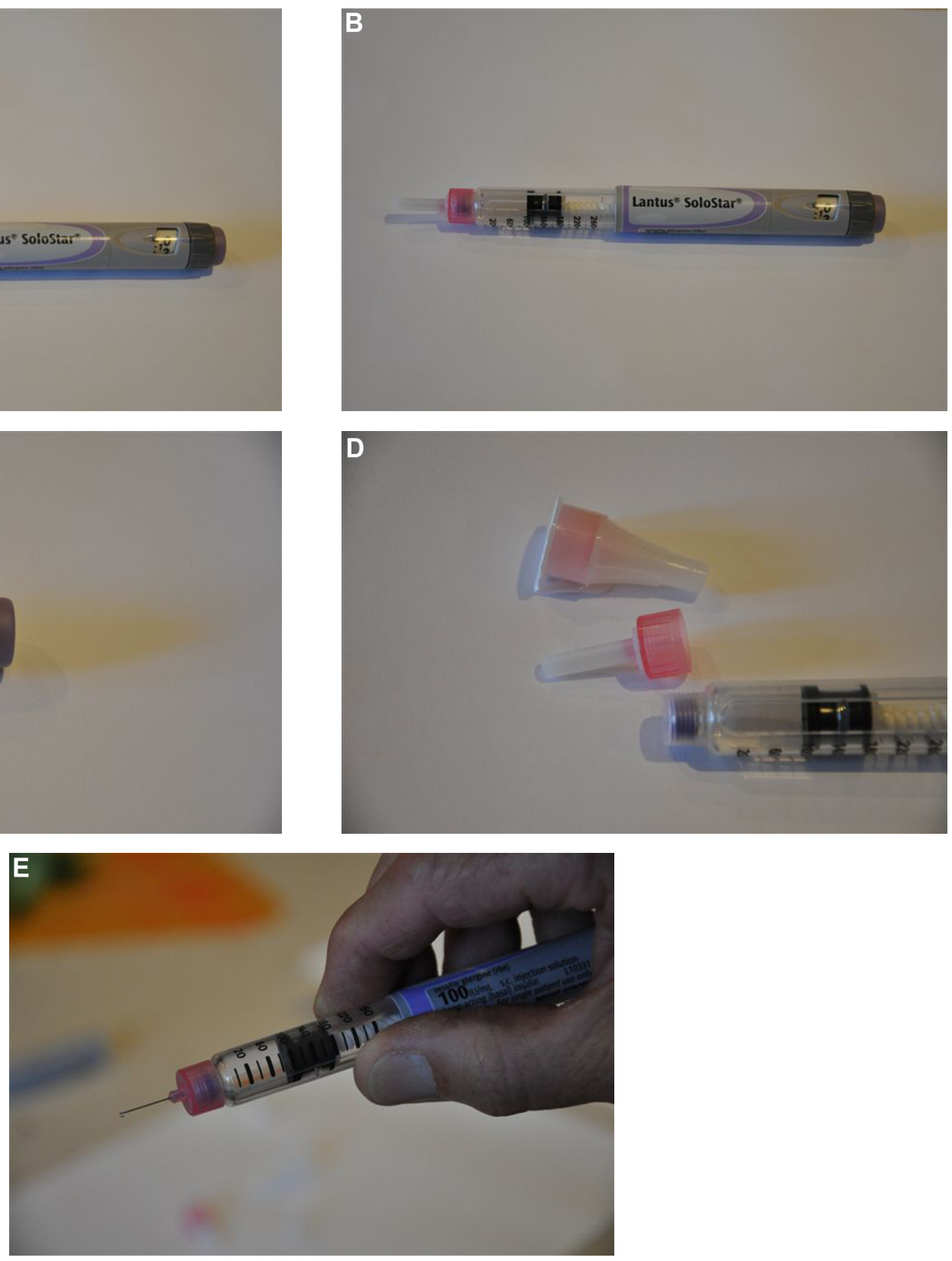

Figure 2 Example of a prefilled, disposable insulin dosing pen, the Lantus SoloStar ${ }^{\circledast}$.

Notes: (A) Pen with cap in place. (B) Pen with cap removed. (C) Close up of the dark gray dose selector dial and the purple release button at the end of the pen. (D) Pen tip with needles. (E) Pen tip with needle attached.

1. A new needle placed for every injection

2. Priming of the pen prior to every injection once the needle is attached

3. Holding the pen in place for the recommended (manufacturer's) time during administration

4. Storage of the pen with no needle attached

5. Storage of the pen at the recommended (manufacturer's) temperature

6. Disposal of the pen vial or pen after the recommended (manufacturer's) days in use.
The reasoning behind some of these recommendations is that the pen cartridges are prone to accumulation of air if incorrectly handled. If a needle is left attached to the pen, air can enter the cartridge, which also increases the risk of bacterial contamination. This is also the rationale behind priming. One or two units are dialed and dispelled with the pen tip facing upward; this is referred to as an air shot (Figure 5). The air shot is repeated as many times as required until a stream of insulin drops is ejected from the needle tip. Priming ensures that insulin, not air, is injected into the 

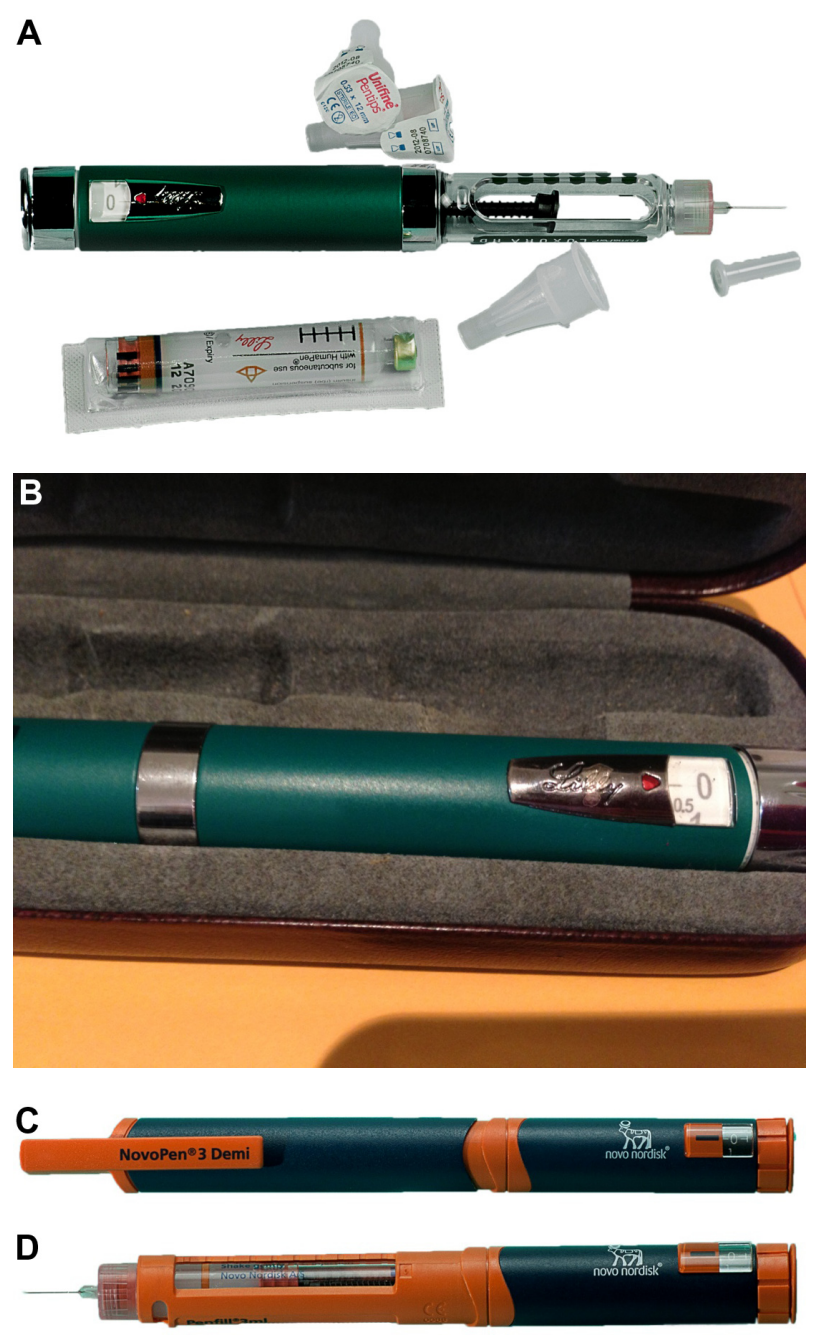

Figure 3 Examples of human pediatric reusable insulin dosing pens that can be loaded with $3 \mathrm{~mL}$ insulin cartridges and deliver doses in $0.5 \mathrm{U}$ increments.

Notes: (A) HumaPen Luxura HD ${ }^{\circledR}$ (Eli Lilly). (B) Close up of the silver dose selector dial and release button at the end of the HumaPen Luxura HD pen. (C) NovoPen 3 Demi $^{\circledR}$ (Novo Nordisk). (D) NovoPen 3 Demi with the cap removed and an insulin cartridge and needle in place.

patient. The perceived wastage of insulin with the air shot is a misconception. A human study comparing wastage of insulin in people using vials and syringes versus pens and cartridges showed an overall wastage of almost 30\% less in those using pens. ${ }^{33}$ The decreased insulin wastage with pens was thought to be due to improved accuracy when dosing. Because of the mechanics of pen devices, it can take several seconds for the insulin to be delivered once the pen is deployed. Different devices have different insulin delivery times, so the manufacturer's recommendations should be adhered to. If the needle is withdrawn prematurely, the patient might be underdosed. Most veterinary clients do not have problems holding the pen for 5-10 seconds, but if problems are encountered, see the trouble-shooting section below. In an as yet unpublished study (Stewart et al,
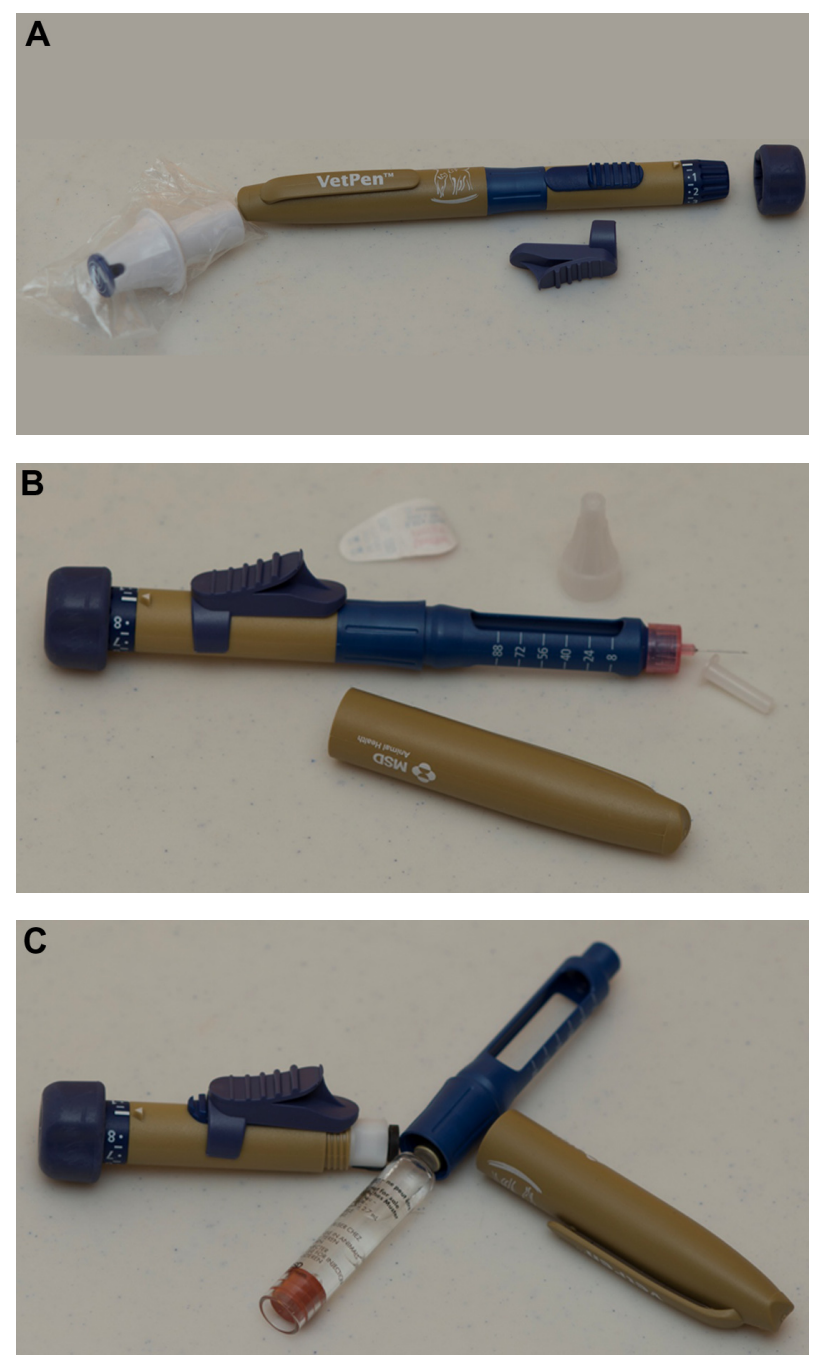

Figure 4 VetPen ${ }^{\circledast}$ for use with Vetsulin ${ }^{\circledast} /$ Caninsulin $^{\circledast}$.

Notes: (A) VetPen (MSD Animal Health). (B) VetPen with the cap removed and needle in place. (C) VetPen loaded with $2.7 \mathrm{~mL}$ insulin cartridges.

unpublished data, 2014) to determine how well cats would tolerate a 10 -second injection with an insulin pen, 30/36 normal cats required only passive restraint (no scruffing) for a 10-second injection of saline using a glargine insulin pen; the other six cats allowed a 10 -second injection with only light scruffing (mostly to keep them from jumping off the examination table; Figure 6). Once in use, most manufacturers recommend to store the pen away from light and at room temperature below $25^{\circ} \mathrm{C}$ or $77^{\circ} \mathrm{F}$. Large fluctuations in temperature can affect the insulin activity and concentration. The associated pressure changes within the cartridge can cause air to accumulate or insulin to leak from the cartridge via the needle holes. Human diabetics also report decreased pain associated with injection of insulin at room temperature. Disposing of insulin once it has been in use for the recommended period is to maintain the correct insulin 


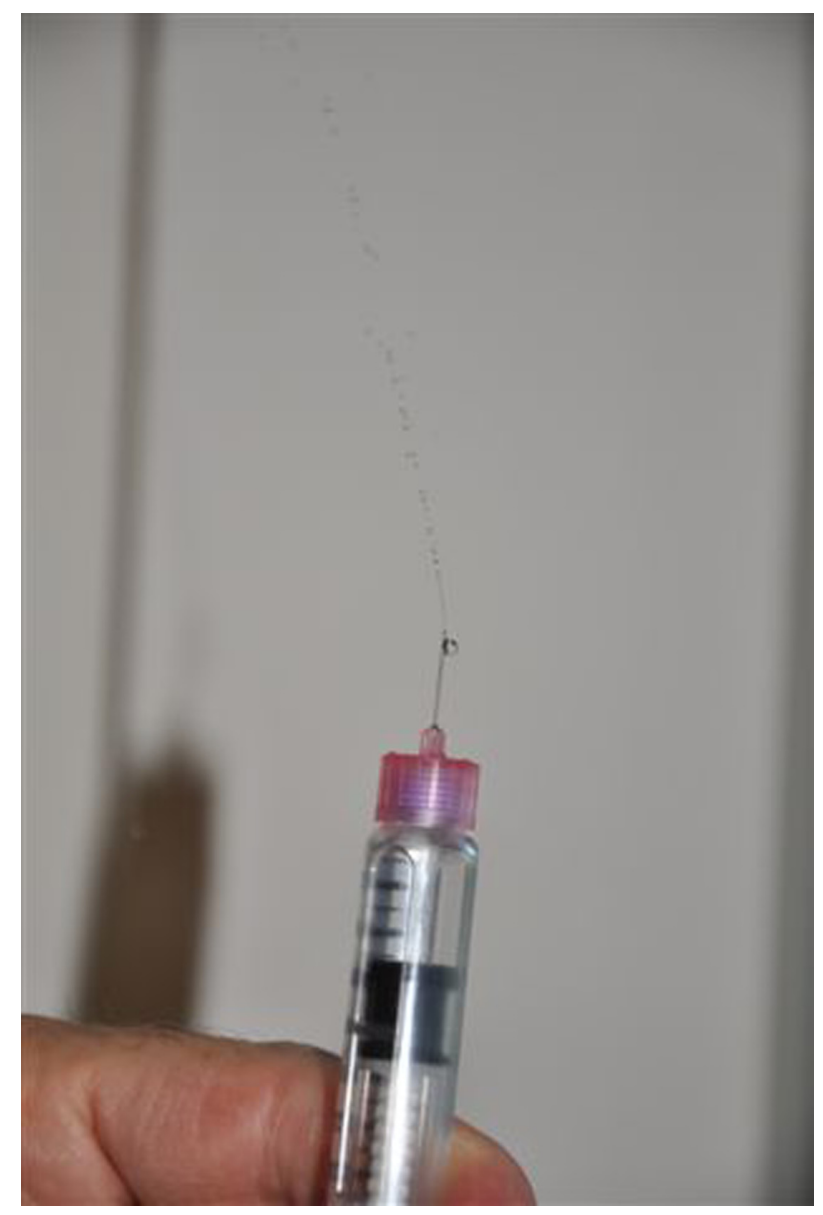

Figure 5 Air shot. One or two units of insulin are dialed and dispelled with the pen tip facing upward. This ensures that the pen is operating correctly and insulin, not air, is injected into the patient.

potency and decrease the risk of contamination. With careful handling and refrigerated storage, it has been suggested that at least some insulin preparations can be safely used for between 3 and 6 months. ${ }^{34}$ However, deviating from the manufacturer's recommendations should be undertaken

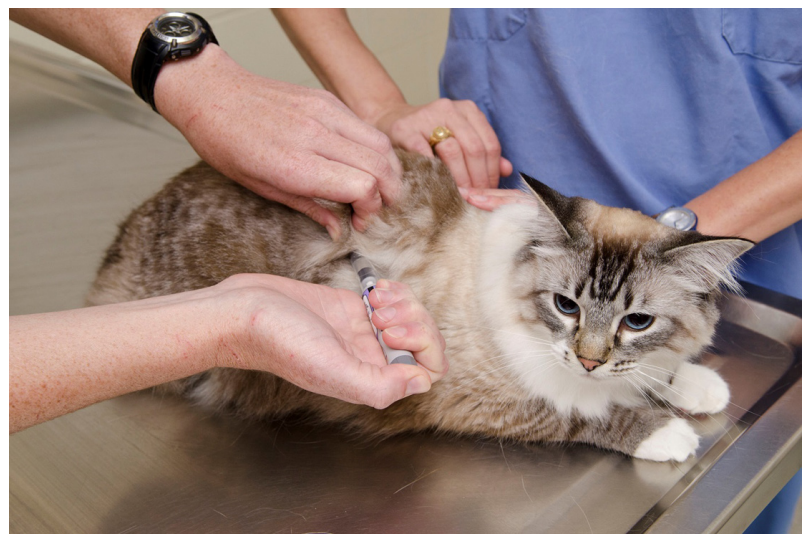

Figure 6 Cat sitting with minimal restraint for 5-10 seconds during simulated insulin administration. cautiously, and owners must be advised to discard insulin if it becomes discolored or more cloudy than usual.

\section{Cost of pens versus syringes}

The initial set-up for reusable pens might be higher than for syringes, although costs of pens and insulin preparations vary significantly depending on the country, and manufacturers of human insulin will often provide the reusable pens at no charge. The cost of pen needles is similar to or less than the cost of insulin syringes (may vary depending on country), hence ongoing costs of disposals are comparable.

A cat receiving glargine at $2 \mathrm{U}$ every 12 hours will use $224 \mathrm{U}$ of a $300 \mathrm{U}$ prefilled insulin dosing pen in 28 days (including air shots). This will result in "wastage" of $112 \mathrm{U}$ of insulin in air shots and $76 \mathrm{U}$ of unused insulin when the vial is discarded after 28 days. However, the same recommendations are in place for an open $10 \mathrm{~mL}$ vial of glargine insulin. The same cat would use $112 \mathrm{U}$ of a 1,000 U vial (assuming accurate syringe dosing and negligible wastage in the hub of the needle), resulting in wastage of $888 \mathrm{U}$ of unused insulin when the vial is discarded 28 days after first use.

One benefit of insulin dosing pens is that insulin vials are smaller and so are changed more regularly. This minimizes the risk that insulin might become deactivated during prolonged use of one insulin vial. For example, a dog receiving $2 \mathrm{U}$ Caninsulin/Vetsulin every 12 hours will use $252 \mathrm{U}$ in 6 weeks (including air shots). Each $2.7 \mathrm{~mL}$ vial contains $108 \mathrm{U}$, so the entire vial will be used well before the 6-week expiry date. Assuming accurate syringe dosing and negligible wastage in the hub of the needle, the same dog would use $168 \mathrm{U}$ with syringe dosing, and so a $4 \mathrm{~mL} 160 \mathrm{U}$ vial will last for almost the entire 6-week period, whereas if a $10 \mathrm{~mL} 400 \mathrm{U}$ vial was used, $232 \mathrm{U}$ would need to be discarded at expiry.

\section{Available pens}

Once an appropriate insulin type has been selected based on the specific requirements of the diabetic patient, then syringes and vials or pen devices and cartridges can be chosen. The list below is meant as a guide listing the pen devices that are currently available and their features.

Caninsulin/Vetsulin is the only veterinary insulin product that also has an insulin pen for veterinary patients. Two pens are available, a maximum $8 \mathrm{U} /$ dose VetPen ${ }^{\circledR}(0.5-8.0$ $\mathrm{U})$ with dosing increments of $0.5 \mathrm{U}$, and a maximum 16 $\mathrm{U} /$ dose VetPen (1-16 U) with dosing increments of $1 \mathrm{U}$ (Figure 4). The pens are plastic but reusable, and have been tested up to 3,000 uses, which would be over 4 years in a diabetic on twice-daily insulin. Once the dose is selected, 
the pen dial cannot be turned back to a lower dose, and users are instructed to not forcefully dial back as this may damage the pen. It is recommended that the incorrect dose of insulin be dispelled and then the correct dose selected. Once in use, the pen can be stored in the refrigerator or at room temperature no higher than $25^{\circ} \mathrm{C}$ or $77^{\circ} \mathrm{F}$, although storage recommendations differ because of drug regulations in individual countries. Insulin cartridges should be discarded after 6 weeks of use. It is recommended that the needle is kept in the skin for 5 seconds during dosing with the VetPen.

\section{Pens for use with Novo Nordisk insulin}

Disposable prefilled Novo Nordisk pens include the Innolet pen, FlexPen ${ }^{\circledR}$, and the FlexTouch ${ }^{\circledR}$. The Innolet pen has a large ergonomic dial face that makes it easy to use for people with vision problems or manual dexterity issues such as arthritis (Figure 1). It dispenses whole units only up to a maximum dose of $50 \mathrm{U}$. The Flexpen is a standard plastic pen-style device that dispenses whole units up to $60 \mathrm{U}$. FlexTouch is a new spring-loaded disposable pen that delivers whole units up to $80 \mathrm{U}$, currently only available with detemir insulin.

Reusable NovoPen ${ }^{\circledR}$ pens include the NovoPen 5, NovoPen 4, NovoPen 3 Demi (Figure 3C and D), NovoPen Junior, and the NovoPen Echo. The NovoPen 4 (1-60 U) dispenses whole units and it has been shown to be accurate for 5 years of dosing and has a click at the end of the dose (useful for knowing when the dose has been delivered). NovoPen 5 (1-60 U) has the same features, but has a digital dial face on the end of the pen that will display the last dose and how many hours since it was administered. The NovoPen 3 delivers whole units (2-70 U). Pens that deliver half units include the NovoPen 3 Demi (1-35 U) and NovoPen Junior (1-35 U), and the NovoPen Echo $(0.5-30 \mathrm{U})$ has the special feature of a digital dial and memory. All Novo Nordisk pens are designed to be used with NovoFine ${ }^{\circledR}$ or NovoTwist ${ }^{\circledR}$ needles, although generic pen needles are also available. It is recommended that the needle is kept in the skin for 6 seconds during dosing with NovoPen pens.

\section{Pens for use with Eli Lilly insulin}

$\mathrm{KwikPen}^{\circledR}$ pens are disposable and prefilled, and deliver whole units, from $1 \mathrm{U}$ to $60 \mathrm{U}$. The reusable pens are HumaPen Savvio ${ }^{\circledR}$, HumaPen Memoir ${ }^{\circledR}$, HumaPen Luxura $^{\circledR}$, and HumaPen Luxura HD ${ }^{\circledR}$ (Figure 3A and B). The HumaPen Savvio delivers whole units up to $60 \mathrm{U}$ and comes in a large array of colors. HumaPen Memoir delivers whole units up to $60 \mathrm{U}$. It has a digital face and a memory that records the last 16 doses. HumaPen Luxura HD delivers half-unit doses from $0.5 \mathrm{U}$ to $30 \mathrm{U}$ while the HumaPen Luxura delivers whole units up to $60 \mathrm{U}$. The HumaPen Luxura, which delivers whole unit doses, is no longer available in some countries. Becton, Dickinson, and Company pen needles are recommended for all Eli Lilly pens, but generic needles are available. It is recommended that the needle is kept in the skin for 5 seconds during dosing with Eli Lilly pens.

\section{Pens for use with Sanofi insulin}

Pens for use with Sanofi insulin include the disposable SoloSTAR ${ }^{\circledR}$ pen that administers whole units up to $80 \mathrm{U}$. The ClickSTAR $^{\circledR}(1-80 \mathrm{U}), \operatorname{ALLSTAR}^{\circledR}(1-80 \mathrm{U})$, and JuniorSTAR $^{\circledR}(1-30 \mathrm{U})$ are reusable pens. The JuniorSTAR pen has the advantage of delivering half units, although the smallest dose it can deliver is $1 \mathrm{U}$. Owen Mumford makes the Autopen $^{\circledR}$ for use with Sanofi insulin products. The Autopen dispenses insulin in $1 \mathrm{U}$ or $2 \mathrm{U}$ increments up to $21 \mathrm{U}$ or $42 \mathrm{U}$, respectively. This pen has an insulin release on the side of the pen similar to the VetPen, rather than the top of the pen as is typical for most human pens. The Sanofi pens can be used with Becton, Dickinson and Company pen needles and the Autopen with Owen Mumford pen needles, although generic needles are also available. It is recommended that the needle is kept in the skin for 10 seconds during dosing with Sanofi pens.

Pen needles are usually between 29 and 32 gauge and come in differing lengths, ranging between $4 \mathrm{~mm}$ and $12.7 \mathrm{~mm}$. The current recommendation in human medicine favors the shorter pen needles; however, the longer 10-12.7 mm needles are recommended for veterinary patients. The technique used for subcutaneous injection is different for dogs and cats compared with people, so if the needle is too short for veterinary patients, there is a risk of intradermal insulin delivery. Once insulin vials are loaded into a pen or a prefilled pen is in use, they should generally be stored out of the refrigerator at room temperature (less than $25^{\circ} \mathrm{C}$ or $77^{\circ} \mathrm{F}$ ) and away from light. However, manufacturer's instructions vary and should always be followed. It is recommended to discard most vials after 28 days or earlier if they become discolored. It is important that all users refer to individual product inserts for specific recommendations, as some insulin preparations recommend vials be discarded after as little as 10 days or up to 42 days. $^{35}$ 


\section{Tips for improving owner compliance}

Compliance is markedly improved if there is a close rapport between the owner and the clinician managing the case and appropriate individualization of the therapeutic and monitoring regimen. Operation of the insulin dosing pen is just one of the many aspects of treatment that owners of a newly diagnosed diabetic pet must become accustomed to. The veterinarian must invest time to educate the owner about diabetes and its management, as well as to provide support and guidance while the owner establishes a practical routine. Follow-up communication is especially important while treatment is being initiated in the home environment. Although written instructions are very helpful and experienced veterinary technicians can provide valuable support, owners also often need to ask questions or discuss individual concerns directly with their veterinarian.

\section{Addressing owner concerns}

Owners are typically very concerned about the potential negative impact of treating a diabetic pet on their lifestyle. Common concerns include difficulties when leaving a diabetic dog or cat with friends or family, worry about the possibility of hypoglycemia, and concerns about adapting social and work life to the pet's treatment regimen. ${ }^{36,37}$ Many people are also very fearful at the prospect of having to administer injections.

The option of using an insulin dosing pen can help to address many of these concerns. Pet owners are more likely to already be familiar with drug administration using a pen than with syringes. For example, those who work with children often receive training in use of epinephrine auto-injectors $\left(\right.$ Epi-Pen $\left.^{\circledR}\right)$, women participating in in vitro fertilization programs administer hormone treatments using dosing pens, and diabetic people typically use insulin dosing pens rather than syringes. Owners therefore often find an insulin dosing pen less confronting than syringes and acknowledge that it will be easier to ask friends or family to learn to use it. It is a relief for many to understand that dosing is more accurate and that the risk of accidental overdose is substantially reduced compared with syringes.

\section{Instructing owners on how to use an insulin dosing pen}

A face-to-face consultation with the owner and the diabetic pet is always required. It is important to never assume that anyone already knows how to use an insulin dosing pen, even if they claim to be experienced. Veterinarians who are not familiar with an insulin dosing pen are strongly encouraged to review the manufacturer's instructions, and to assemble and test the pen prior to the consultation with the owner.

Insulin dosing pens all function in a similar manner, although there are minor differences. Manufacturers provide useful written instructions that can be used as a guide during the consultation and later referred to by owners at home. The following check list may also be used when instructing owners on use of the pen:

1. Familiarize with the components of the pen, including operation of the dose selector dial and the release trigger.

2. Practice one-handed operation of the pen. For most people, the most comfortable approach is to hold the pen against the palm with the four fingers and then use the thumb to press the trigger.

3. For reusable pens, load an insulin cartridge into the pen. This step is not necessary with prefilled insulin dosing pens.

4. Always mix the insulin before each injection, typically by rolling the pen ten times and then inverting the pen ten times. This is crucial for insulin suspensions such as Caninsulin/Vetsulin (MSD Animal Health), but also advisable for solutions such as Lantus (glargine) insulin (Sanofi).

5. Prime the insulin dosing pen. Attach the needle onto the pen, use the dose selector to dial the priming dose of either 1 or 2 units according to the manufacturer's instructions, hold the pen vertically with the needle upward, and push the release button. The goal is for a stream of insulin to be ejected from the needle tip. If a stream is not seen, the pen must be primed again until this is achieved. Pens might need to be primed several times when an insulin cartridge is first inserted. This process ensures there is no air in the system and provides reassurance that the pen is working properly.

6. Practice operating the pen with the dose that will be prescribed for the pet. Use the dose selector to dial the recommended dose and then use a one-handed grip of the pen to push the release trigger. It can be helpful to advise the owner to note the time taken for the pen to deliver the dose as this provides a practical guide for how long the needle must be left in the animal's skin during injection.

7. Finally, observe the owner's technique as they administer their first injection with the insulin dosing pen. Counsel against rushing the process by recommending that four successive steps are used: gently pinch up the pet's skin; slide the needle through the skin; press the release trigger; and withdraw the needle. 
8. Check that the dose selector dial has returned to the "0" position, which confirms that the full insulin dose was delivered. Note that it is normal for a drop of insulin to be seen on the needle tip after removing the needle from the injection site. There is no need to be concerned that the full dose was not delivered if the drop is seen.

\section{Owners with needle phobia}

People with needle phobia are often much more comfortable handling an insulin dosing pen than syringes and needles. However, the most confronting part of the injection process for most is the insertion of the needle through the skin and this is still required with pen dosing. One tip that can help owners cope with this is to inject into an area of skin covered with plenty of hair as this shields the vision of the needle entering the skin. Routine clipping of a window in the hair coat to assist with instruction on injection technique is therefore not recommended as it can make people with needle phobia more uncomfortable. It can also sometimes give the false impression that the clipped area is a preferred injection site and so discourage owners from the correct practice of rotating through a wide variety of injection sites.

\section{Dogs with aggression when injected}

This is perhaps the most challenging situation for owners of a newly diagnosed diabetic dog and it often is advisable for them to consult with a veterinary behaviorist. In most cases, a reward-based training approach is used to teach the dog compliance with insulin injections. A protocol is required where the dog is rewarded with its favorite thing (for example, food, a ball, putting the lead on for a walk) after every injection. It generally helps to have at least two people present in the initial stages. The dog is typically asked to sit and stay and then be shown its favorite thing. When the dog is totally focused on its favorite thing, the injection is given while the other person gives the dog its favorite thing. Success can often be achieved by simply instructing the owner to inject while the dog is eating. Some dogs will need to be muzzled. The dog can be trained to accept the muzzle by putting a treat in the muzzle and then gently strapping it on while the dog eats the treat. The muzzle is then removed immediately after the injection, and another reward given.

It appears to be important that the routine of the rewardbased training is continued strictly for about 3 weeks as dogs that comply initially will often display aggression on a single occasion after 1-2 weeks and it seems that, if they do not get away with it that time, they will then comply with injections in the long term with no problem.

\section{Trouble-shooting}

\section{The insulin dosing pen will not prime properly}

- The pen has been stored with the needle attached. Insulin might potentially leak out and/or air might leak into the insulin cartridge. Solution: repeat the priming process until all air is pushed from the cartridge.

- The needle has not been screwed onto the end of the pen correctly; for example, the inner needle might have bent and not pierced the rubber seal of the insulin cartridge. Solution: replace the needle.

- The insulin cartridge is cracked or chipped. Solution: replace the insulin cartridge in reusable pens; replace the pen if using a prefilled pen.

- Foreign material is interfering with the pen mechanism. For example, this can occur with reusable pens when small pieces of glass from a damaged insulin cartridge get into the mechanism.

Solution: open the pen and set aside the section that houses the insulin cartridge. Operate the pen so that the piston moves out of its housing and the foreign material is released. For most pens, this can be achieved by repeatedly using the dose selector to dial up large doses and pressing the release trigger.

\section{The needle is bent after use}

Pen needles are designed to bend rather than break if there is movement during injection. Solution: no action is required. The full insulin dose can be administered through a bent needle.

\section{There is a drop of insulin on the tip of the needle after injection}

This is normal. The drop will sometimes disperse into the animal's coat and other times be visible on the needle tip. Solution: run fingers over injection site to ensure that the area is not wet with insulin. If the skin surface feels dry, the full dose has been delivered.

\section{The dose selector dial does not return to the " 0 " position}

The full dose has not been delivered because the release trigger was not fully pressed. Solution: the remainder of the dose can be administered by injecting again. It is important to use the same needle and to not prime the pen again prior to injecting the remainder of the dose. To avoid accidental insulin overdose, the safest approach might be to instruct owners to never "top up" an insulin dose that they think might not have been administered fully. 


\section{The pen primes properly, but it is difficult to press the release trigger during injection}

This usually means that insulin is being injected into the skin or other tissues rather than the subcutaneous space. Solution: review the owner's injection technique. It is also recommended that the pen needles are checked. Most brands of pen needles will fit onto most insulin dosing pens and owners might obtain needles from sources other than their veterinarian. Diabetic people typically use much shorter needles (for example, 4, 6, or $8 \mathrm{~mm}$ long) than are recommended for dogs and cats (10 or $12 \mathrm{~mm}$ long pen needles). These shorter needles will sometimes not pass all the way through the skin, resulting in intradermal administration of insulin.

\section{The insulin does not seem to be effective}

- The pen is not working properly. Solution: ensure that the pen is primed correctly before each dose.

- The insulin suspension has not been thoroughly mixed prior to each injection. Solution: review the owner's injection technique.

- The insulin is not being injected. Solution: review the owner's injection technique.

- The insulin has been inactivated by exposure to temperatures $>30^{\circ} \mathrm{C} / 85^{\circ} \mathrm{F}$ or light for prolonged periods. Solution: check that the pen cap is replaced after each injection and clicks firmly into place. Review the storage conditions for insulin dosing pens that do not require refrigeration and for the insulin cartridges prior to use. An expedient method of ruling out the possibility of inactivated insulin is to change to a new insulin cartridge or prefilled insulin dosing pen.

\section{Unexpected hypoglycemia}

The insulin suspension has not been thoroughly mixed prior to each injection. Solution: review the owner's injection technique.

\section{Conclusion}

Insulin pen devices are not right for all human diabetic patients and they will not be the right choice for all of our veterinary patients. With this in mind, pen devices do have many benefits over the standard vial and syringe method of insulin administration, including improved dose accuracy, less pain on administration, and potentially less insulin wastage. Veterinarians who care for diabetic patients need to be aware of this method of insulin delivery and familiarize themselves with the products available, specifically manufacturers' recommendations for the insulin and devices they dispense. Teaching our clients correct procedure is imperative in our combined goal of achieving improved glycemic control for their pets.

\section{Disclosure}

LF has received honoraria for educational seminars convened by MSD Animal Health during the past 3 years, but has no other financial interest in companies that make insulin or insulin pens. LF has also received honoraria for educational seminars and advisory committees on behalf of companies in the general veterinary field. PL has received an unspecified grant from Merck Animal Health for diabetic cat research. AT has no financial interest in companies in the general veterinary field or in those that make insulin or insulin or pens.

\section{References}

1. Maggiore AD, Nelson RW, Dennis J, Johnson E, Kass PH. Efficacy of protamine zinc recombinant human insulin for controlling hyperglycemia in dogs with diabetes mellitus. J Vet Intern Med. 2012;26(1): 109-115.

2. Sears KW, Drobatz KJ, Hess RS. Use of lispro insulin for treatment of diabetic ketoacidosis in dogs. J Vet Emerg Crit Care. 2012;22(2) 211-218.

3. Palm CA, Boston RC, Refsal KR, Hess RS. An investigation of the action of neutral protamine Hagedorn human analogue insulin in dogs with naturally occurring diabetes mellitus. JVet Intern Med. 2009;23(1): 50-55.

4. Hoelmkjaer KM, Spodsberg EM, Bjornvad CR. Insulin detemir treatment in diabetic cats in a practice setting. J Feline Med Surg. 2015 17(2):144-151.

5. Roomp K, Rand J. Evaluation of detemir in diabetic cats managed with a protocol for intensive blood glucose control. J Feline Med Surg. 2012; 14(8):566-572.

6. Marshall RD, Marshall RD, Rand JS, Morton JM. Treatment of newly diagnosed diabetic cats with glargine insulin improves glycaemic control and results in higher probability of remission than protamine zinc and lente insulins. J Feline Med Surg. 2009;11(8):683-691.

7. Marshall RD, Rand JS, Gunew MN, Menrath VH. Intramuscular glargine with or without concurrent subcutaneous administration for treatment of feline diabetic ketoacidosis. J Vet Emerg Crit Care. 2013 23(3):286-290.

8. Bode BW, Buse JB, Fisher M, et al. Insulin degludec improves glycaemic control with lower nocturnal hypoglycaemia risk than insulin glargine in basal-bolus treatment with mealtime insulin aspart in type 1 diabetes (BEGIN ${ }^{\circledR}$ Basal-Bolus Type 1): 2-year results of a randomized clinical trial. Diabet Med. 2013;30(11):1293-1297.

9. DeClue AE, Leverenz EF, Wiedmeyer CE, Bryan ME, Reinero CR. Glucose lowering effects of inhaled insulin in healthy cats. J Feline Med Surg. 2008;10(5):519-522.

10. Humulin ${ }^{\circledR} \mathrm{N}$ [package insert]. Indianapolis, IN, USA: Eli Lilly and Company; 2013.

11. Novolin ${ }^{\circledR} \mathrm{N}$ [package insert]. Bagsvaerd, Denmark: Novo Nordisk; 2013.

12. Wilson S. Is Walmart NPH insulin (Novolin) as effective as Humulin? Available from: http:/www.vin.com/Members/Boards/DiscussionViewer.aspx?documentid=6499540\&ViewFirst=1. October 29, 2014. 
13. Graham PA, Nash AS, McKellar QA. Pharmacokinetics of a porcine insulin zinc suspension in diabetic dogs. J Small Anim Pract. 1997; 38(10):434-438.

14. Fleeman LM, Rand JS, Morton JM. Pharmacokinetics and pharmacodynamics of porcine insulin zinc suspension in eight diabetic dogs. Vet Rec. 2009;164(8):232-237.

15. Fracassi F, Hafner M, Corradini S, Boretti F, Sieber-Ruckstuhl N, Reusch C. Use of insulin detemir in dogs with diabetes mellitus. Paper presented at the European College of Veterinary Internal Medicine-Companion Animal Congress, Maastricht, The Netherlands, September 6-8, 2012.

16. Ford SL, Rand JS, Ghormley TM, Lynch HM. Evaluation of detemir insulin in diabetic dogs managed with home blood glucose monitoring. Paper presented at the American College of Veterinary Internal Medicine Forum, Anaheim, CA, USA, June 9-12, 2010.

17. European Medicines Agency. Initial scientific discussion for the approval of levemir. Available from: http://www.ema.europa.eu/ docs/en_GB/document_library/EPAR_-_Scientific_Discussion/ human/000528/WC500036658.pdf. December 14, 2014.

18. Hess RS, Drobatz KJ. Glargine insulin for treatment of naturally occurring diabetes mellitus in dogs. J Am Vet Med Assoc. 2013;243(8): 1154-1161.

19. Maggiore AD, Nelson RW, Dennis J, Johnson E. Efficacy of protamine zinc recombinant human insulin for controlling hyperglycemia in dogs with diabetes mellitus. $J$ Vet Intern Med. 2012;26(1):109-115.

20. Wallace MS, Peterson ME, Nichols CE. Absorption kinetics of regular, isophane, and protamine zinc insulin in normal cats. Domest Anim Endocrinol. 1990;7(4):509-515.

21. Nelson RW, Henley K, Cole C. Field safety and efficacy of protamine zinc recombinant human insulin for treatment of diabetes mellitus in cats. J Vet Intern Med. 2009;23(4):787-793.

22. Roomp K, Rand J. Intensive blood glucose control is safe and effective in diabetic cats using home monitoring and treatment with glargine. J Feline Med Surg. 2009;11(8):668-682.

23. Michiels L, Reusch CE, Boari A, et al. Treatment of 46 cats with porcine lente insulin - a prospective, multicentre study. J Feline Med Surg. 2008;10(5):439-451.

24. Bennett N, Greco DS, Peterson ME, Kirk C, Mathes M, Fettman MJ. Comparison of a low carbohydrate-low fiber diet and a moderate carbohydrate-high fiber diet in the management of feline diabetes mellitus. J Feline Med Surg. 2006;8(2):73-84.
25. Zini E, Hafner M, Osto M, et al. Predictors of clinical remission in cats with diabetes mellitus. J Vet Intern Med. 2010;24(6):1314-1321.

26. Scott-Moncrieff JC, Moore GE, Coe J, Lynn RC, Gwin W, Petzold R. Characteristics of commercially manufactured and compounded protamine zinc insulin. J Am Vet Med Assoc. 2012;240(5):600-605.

27. Plumb DC. Plumb's Veterinary Drug Handbook. Stockholm, WI, USA: Pharma Vet Inc.; 2011.

28. Graff MR, McClanahan MA. Assessment by patients with diabetes mellitus of two insulin pen delivery systems versus a vial and syringe. Clin Ther. 1998;20(3):486-496.

29. Keith K, Nicholson D, Rogers D. Accuracy and precision of low-dose insulin administration using syringes, pen injectors, and a pump. Clin Pediatr (Phila). 2004;43(1):69-74.

30. Casella SJ, Mongilio MK, Plotnick LP, Hesterberg MP, Long CA. Accuracy and precision of low-dose insulin administration. Pediatrics. 1993;91(6):1155-1157.

31. Gnanalingham M, Newland P, Smith C. Accuracy and reproducibility of low dose insulin administration using pen-injectors and syringes. Arch Dis Child. 1998;79(1):59-62.

32. Mitchell VD, Porter K, Beatty SJ. Administration technique and storage of disposable insulin pens reported by patients with diabetes. Diabetes Educ. 2012;38(5):651-658.

33. Krahulec B, Strbová L, Seböková E, Cárský J, Klimes I. [Comparison of insulin loss in treatment of diabetics using the classical syringe or the insulin pen (Novopen II)]. Vnitr Lek. 1996;42(9):640-645. Slovak.

34. Roomp K, Rand JS. Management of diabetic cats with long-acting insulin. Vet Clin North Am Small Anim Pract. 2013;43(2):251-266.

35. Pearson TL, Pearson TL. Practical aspects of insulin pen devices. J Diabetes Sci Technol. 2010;4(3):522-531.

36. Niessen SJ, Powney S, Guitian J, et al. Evaluation of a quality-of-life tool for dogs with diabetes mellitus. J Vet Intern Med. 2012;26(4): 953-961.

37. Niessen SJ, Powney S, Guitian J, et al. Evaluation of a quality-of-life tool for cats with diabetes mellitus. J Vet Intern Med. 2010;24(5): 1098-1105.
Veterinary Medicine: Research and Reports

\section{Publish your work in this journal}

Veterinary Medicine: Research and Reports is an international, peer-reviewed, open access journal publishing original research, case reports, editorials, reviews and commentaries on all areas of veterinary medicine. The manuscript management system is completely online and includes a very quick and fair peer-review system.

\section{Dovepress}

Visit http://www.dovepress.com/testimonials.php to read real quotes from published authors. 